08;09

\title{
Лазерная генерация перенесенных на кремний инжекционных микродисков с квантовыми точками InAs/InGaAs/GaAs
}

\author{
() А.Е. Жуков ${ }^{1}$, Э.И. Моисеев ${ }^{1}$, А.М. Надточий ${ }^{1}$, А.С. Драгунова ${ }^{1}$, Н.В. Крыжановская ${ }^{1}$, \\ М.М. Кулагина ${ }^{2}$, А.М. Можаров ${ }^{3}$, С.А. Кадинская ${ }^{3}$, О.И. Симчук ${ }^{3}$, Ф.И. Зубов ${ }^{3}$, М.В. Максимов ${ }^{3}$ \\ ${ }^{1}$ Национальный исследовательский университет „Высшая школа экономики“, Санкт-Петербург, Россия \\ ${ }^{2}$ Физико-технический институт им. А.Ф. Иофффе РАН, Санкт-Петербург, Россия \\ ${ }^{3}$ Санкт-Петербургский национальный исследовательский Академический университет им. Ж.И. Алфёрова РАН, \\ Санкт-Петербург, Россия \\ E-mail: zhukale@gmail.com
}

Поступило в Редакцию 24 апреля 2020г.

В окончательной редакции 6 мая 2020г.

Принято к публикации 6 мая 2020г.

\begin{abstract}
Микродисковые лазеры $\mathrm{AlGaAs} / \mathrm{GaAs}$ с квантовыми точками $\mathrm{InAs} / \mathrm{InGaAs}$ были перенесены на поверхность кремниевой пластины с помощью индиевого припоя. Микролазеры имеют общий электрический контакт, нанесенный поверх остаточной подложки $n^{+}-\mathrm{GaAs}$, а индивидуальная адресация достигается за счет размещения микродисков p-контактом вниз на раздельные контактные площадки на кремнии. Не выявлено влияния чужеродной подложки на электрические, пороговые, тепловые и спектральные характеристики. Микродиски способны работать в непрерывном режиме без принудительного охлаждения с пороговой плотностью тока около $0.7 \mathrm{kA} / \mathrm{cm}^{2}$. Длина волны генерации стабильна $(<0.1 \mathrm{~nm} / \mathrm{mA})$ по отношению к току инжекции.
\end{abstract}

Ключевые слова: полупроводниковые лазеры, микродисковый лазер, наноструктуры, гибридная интеграция.

DOI: 10.21883/PJTF.2020.16.49844.18354

В последние десятилетия значительные усилия были направлены на разработку лазерных источников на основе прямозонных полупроводников $\mathrm{A}_{3} \mathrm{~B}_{5}$, синтезированных на кремниевых подложках, что обусловлено перспективами реализации быстродействующих лазерных систем оптической связи, интегрированных с кремниевой электроникой и транзисторной логикой $[1,2]$. Были продемонстрированы низкопороговые лазеры полосковой конструкции, созданные на основе системы материалов (Al) GaAs с активной областью, представляющей собой массивы самоорганизующихся квантовых точек $\mathrm{In}(\mathrm{Ga}) \mathrm{As}[3,4]$. Применение лазерных гетероструктур $\mathrm{AlGaAs} / \mathrm{GaAs}$ позволяет реализовать бо́льшие (по сравнению с гетероструктурами InGaAlP/InP) разрывы зон на гетерограницах, тогда как квантовые точки способствуют снижению чувствительности к дефектам и достижению длины волны генерации в одном из спектральных диапазонов оптической связи около $1.3 \mu \mathrm{m}$. Недавно также были созданы первые микродисковые лазеры с квантовыми точками, монолитно интегрированные с кремнием [5-7].

Однако по приборным характеристикам лазеры на основе структур, синтезированных на кремнии, все еще уступают аналогам, выращенным на родных подложках (GaAs) [8], что связано с различиями в полярности, постоянных кристаллических решеток и коэффициентах теплового расширения материалов $\mathrm{A}_{3} \mathrm{~B}_{5}$ и кремния. Избежать проблем, связанных с эпитаксиальным ростом $\mathrm{A}_{3} \mathrm{~B}_{5}$ на $\mathrm{Si}$, позволяет перенос на кремний эпитаксиальных структур или даже готовых микролазеров, синте- зированных на родной подложке. Для этих целей, как правило, используются гетероструктуры, выращенные на подложках InP $[9,10]$, несмотря на то что лазеры на их основе характеризуются низкой температурной стабильностью [11]. В то же время сообщения об использовании для гибридной интеграции лазерных гетероструктур $\mathrm{AlGaAs/GaAs} \mathrm{практически} \mathrm{отсутствуют.}$

Ранее нами было показано, что использование в качестве активной области квантовых точек InAs/InGaAs позволяет реализовать лазерную генерацию при оптической накачке микродисковых лазеров $\mathrm{AlGaAs} / \mathrm{GaAs}$, перенесенных на кремний и закрепленных непроводящим диэлектриком на эпоксидной основе [12,13]. Применение квантовых точек позволяет формировать микролазеры без пассивации и/или заращивания боковых поверхностей, что связано с подавлением поверхностной рекомбинации благодаря локализации носителей заряда в квантовых точках. Впервые о такой особенности квантовых точек сообщалось в [14].

В настоящей работе впервые продемонстрированы работающие при инжекционной накачке в непрерывном режиме микродисковые лазеры с квантовыми точками, синтезированные на подложке GaAs и перенесенные на кремниевую пластину.

Лазерная структура была выращена методом молекулярно-пучковой эпитаксии на подложке $n^{+}$-GaAs (100). Активная область представляет собой десять рядов квантовых точек InAs/InGaAs [15], разделенных нелегированными спейсерными слоями толщиной $35 \mathrm{~nm}$ и помещенных в нелегированный волноводный слой GaAs. Общая 

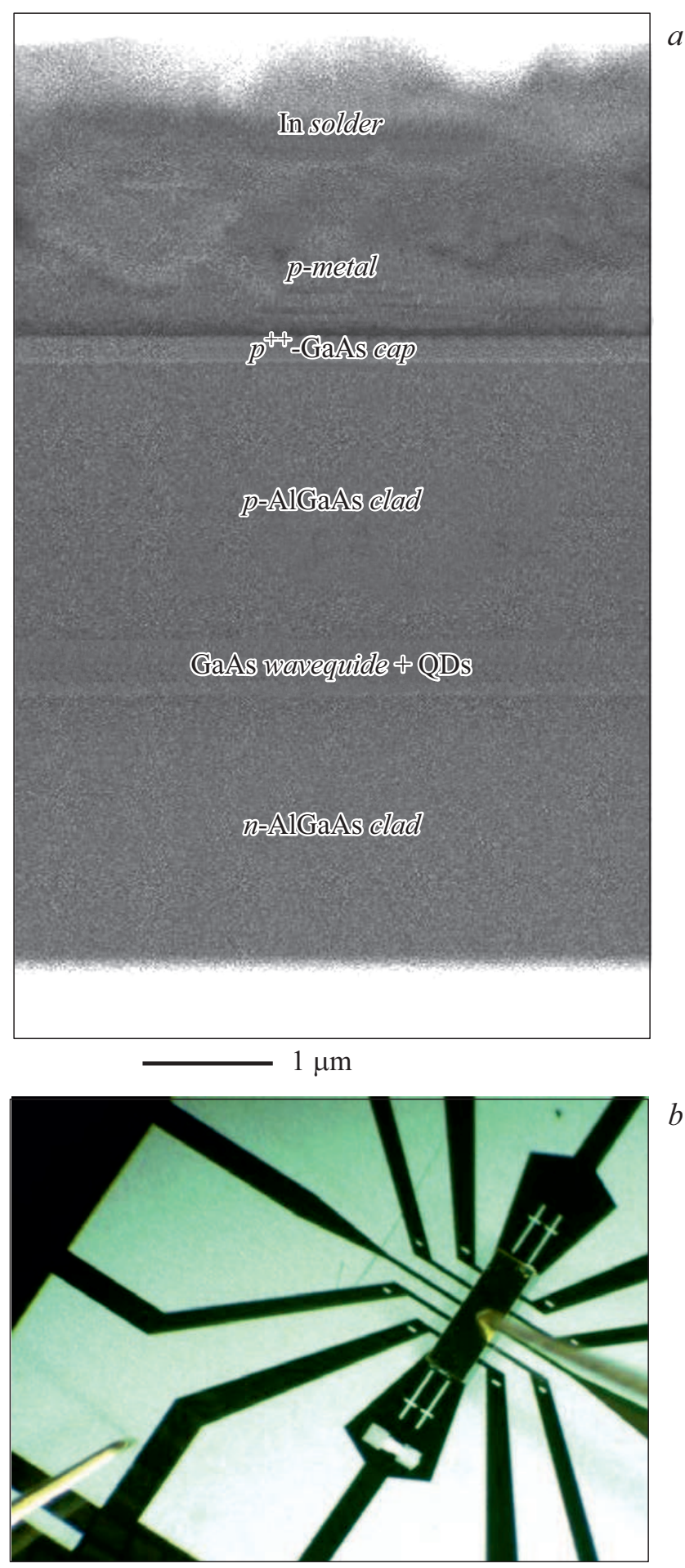

Рис. 1. Микрофотография боковой поверхности микродиска, закрепленного индием на кремниевой пластине $(a)$, и фотография чипа, закрепленного на кремниевой пластине $(b)$.

толщина волновода составляет около $0.44 \mu \mathrm{m}$. Ограничивающие эмиттерные слои $\mathrm{Al}_{0.25} \mathrm{Ga}_{0.75} \mathrm{As}$ имели толщину около $2 \mu \mathrm{m}$ и были легированы кремнием (n-тип) и углеродом ( $p$-тип). Структура заканчивалась контактным слоем $p^{++}$-GaAs толщиной $0.2 \mu \mathrm{m}$ (рис. $1, a$ ).
Длина волны излучения активной области (основной оптический переход квантовых точек) была определена с помощью спектроскопии фотолюминесценции лазерной гетероструктуры равной $1265 \mathrm{~nm}$ при комнатной температуре, полная ширина линии излучения на половине высоты составила $57 \mathrm{~nm}$. Изготовленные из пластины лазеры полосковой конструкции шириной $50 \mu \mathrm{m}$, имеющие сколотые грани и длину резонатора $1 \mathrm{~mm}$, продемонстрировали при импульсной накачке пороговую плотность тока $250 \mathrm{~A} / \mathrm{cm}^{2}$, длина волны лазерной генерации составила $1276 \mathrm{~nm}$.

Микродисковые резонаторы были сформированы с помощью фотолитографии и последующего глубокого (сквозь волновод и активную область) плазмохимического травления цилиндрических мез. Пассивация боковых стенок не проводилась. Индивидуальные электрические контакты круглой формы были изготовлены с помощью металлизации $\mathrm{Ag}-\mathrm{Mn} / \mathrm{Ni} / \mathrm{Au}$, нанесенной на поверхность верхнего слоя $p^{++}$GaAs. Общий электрический контакт был изготовлен с помощью металлизации $\mathrm{Au}-\mathrm{Ge} / \mathrm{Ni} / \mathrm{Au}$ со стороны задней поверхности подложки $n$-GaAs, утоненной до $100 \mu \mathrm{m}$.

Затем подложка с изготовленными микродисками была разделена на отдельные чипы, содержащие массив из $2 \times 6$ микродисков. На поверхности кремниевой пластины с использованием фотолитографии были сформированы контактные площадки и проводящие дорожки $\mathrm{Cr} / \mathrm{Au} / \mathrm{In}$, сгруппированные по 12 штук. Конфигурация площадок соответствовала конфигурации микродисков в массиве, что при переносе обеспечивало индивидуальный электрический контакт к каждому из микродисков. Позиционирование чипа на кремниевой пластине контролировалось с помощью объектива фотолитографа. Чип с микродисками закреплялся на кремниевой пластине индиевым припоем, являющимся верхним слоем контактных площадок. Нагрев выполнялся до $200^{\circ} \mathrm{C}$ с последующим естественным охлаждением.

Электрическое подключение исследуемого микродис-

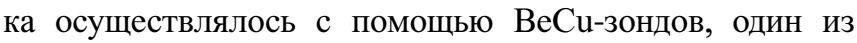
которых (полярность напряжения „--“) устанавливался на общий для всех микродисков контакт на $n$-GaAs, а второй (полярность напряжения „,““) помещался на индивидуальную контактную площадку, сформированную на периферии контактной дорожки на кремниевой пластине (рис. $1, b)$. В настоящей работе представлены результаты для микродиска диаметром $40 \mu \mathrm{m}$.

Измерения проводились при накачке постоянным током от стабилизированного источника питания Keithley 2401. Принудительное охлаждение, а также помещение приборов на дополнительный теплоотвод не применялись. Излучение исследуемого микродиска собиралось 50-кратным объективом Mitutoyo M Plan Apo NIR, передавалось по оптическому волокну и детектировалось оптическим анализатором спектра Yokogawa AQ6370C.

Вольт-амперная характеристика микролазера, перенесенного на кремний (рис. 2), характеризуется напряжением открывания около $1.1 \mathrm{~V}$ и дифференциальным 


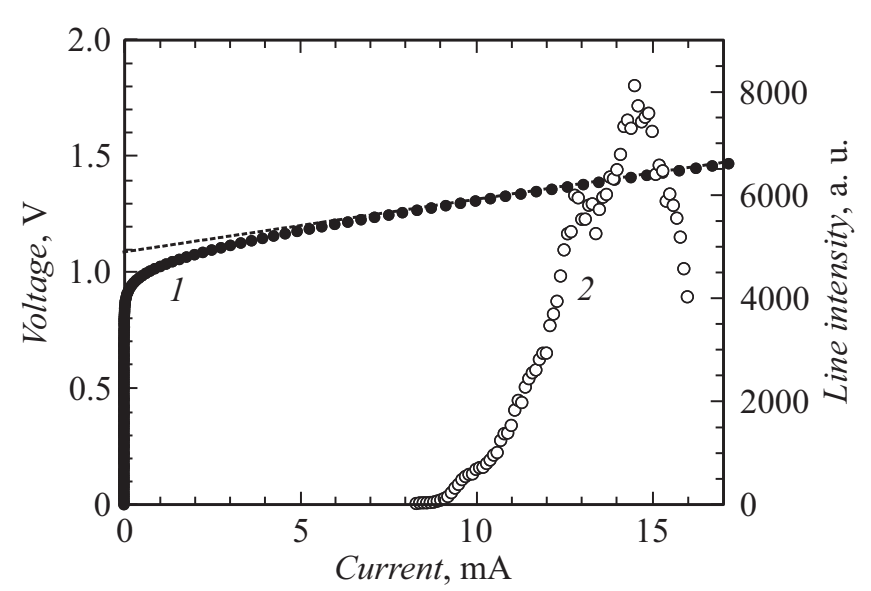

Рис. 2. Напряжение (1) и интегральная интенсивность линии излучения (2) в зависимости от тока накачки микродискового лазера, перенесенного на кремний.

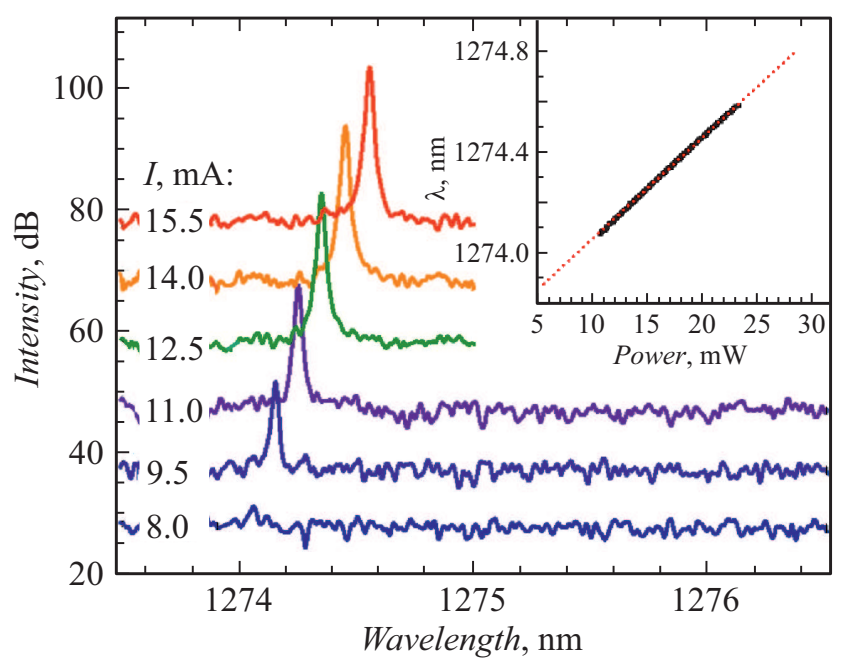

Рис. 3. Спектры излучения микродискового лазера при различных значениях тока накачки I. На вставке - положение максимума излучения в зависимости от электрической мощности. Пунктирная линия соответствует наклону $0.04 \mathrm{~nm} / \mathrm{mW}$.

сопротивлением около $22 \Omega$ (штриховая линия). На рисунке также приведена зависимость интегральной интенсивности линии излучения от тока накачки. Порог лазерной генерации составил $9 \mathrm{~mA}$, что соответствует плотности тока около $0.7 \mathrm{kA} / \mathrm{cm}^{2}$. При токах свыше $14.5 \mathrm{~mA}$ наблюдаются насыщение и последующий спад интенсивности лазерной моды.

Спектры излучения при различных токах накачки показаны на рис. 3 (для наглядности спектры последовательно сдвинуты по оси ординат на $10 \mathrm{~dB}$ ). Ширина линии излучения в режиме генерации составляет около $15 \mathrm{pm}$, что близко к спектральному разрешению измерительной системы. Положение линии излучения соответствует основному оптическому переходу квантовых точек. С ростом накачки линия сдвигается в длинноволновую сторону. Усредненная скорость изме- нения длины волны составляет $0.067 \mathrm{~nm} / \mathrm{mA}$. Нормированный на потребляемую электрическую мощность длинноволновый сдвиг составляет $0.04 \mathrm{~nm} / \mathrm{mW}$ (вставка на рис. 3). Это соответствует тепловому сопротивлению микролазера $0.53 \mathrm{~K} / \mathrm{mW}$.

Таким образом, нами впервые продемонстрирована лазерная генерация при инжекционной накачке в непрерывном режиме перенесенного на кремний микродискового лазера с квантовыми точками. Предложенный метод гибридной интеграции позволяет осуществить индивидуальную адресацию к микродиску. Следует отметить, что электрические, пороговые, спектральные и тепловые характеристики микролазера, перенесенного на кремний, соответствуют значениям, ранее измеренным на исходной подложке GaAs. Представленные результаты подтверждают устойчивость микролазеров на основе квантовых точек к переносу на чужеродную подложку.

\section{Финансирование работы}

Работа выполнена при поддержке Российского научного фонда (соглашение 19-72-30010). Оптические исследования осуществлены в рамках Программы фундаментальных исследований НИУ ВШЭ в 2020 г.

\section{Конфликт интересов}

Авторы заявляют, что у них нет конфликта интересов.

\section{Список литературы}

[1] Болховитянов Ю.Б., Пчеляков О.П. // УФН. 2008. Т. 178. № 5. C. 459-480.

[2] Cornet C., Léger Y., Robert C. Integrated lasers on silicon. London: ISTE Press, 2016. $178 \mathrm{p}$.

[3] Liu A.Y., Zhang C., Norman J., Snyder A., Lubyshev D., Fastenau J.M., Liu A.W.K., Gossard A.C., Bowers J.E. // Appl. Phys. Lett. 2014. V. 104. N 4. P. 041104.

[4] Chen S., Li W., Wu J., Jiang Q., Tang M., Shutts S., Elliott S.N., Sobiesierski A., Seeds A.J., Ross I., Smowton P.M., Liu H. // Nature Photon. 2016. V. 10. N 5. P. 307-311.

[5] Wan Y., Norman J., Li Q., Kennedy M.J., Liang D., Zhang C., Huang D., Zhang Z., Liu A.Y., Torres A., Jung D., Gossard A.C., Hu E.L., Lau K.M., Bowers J.E. // Optica. 2017. V. 4. N 8. P. $940-944$.

[6] Kryzhanovskaya N., Moiseev E., Polubavkina Yu., Maximov M., Kulagina M., Troshkov S., Zadiranov Yu., Guseva Yu., Lipovskii A., Tang M., Liao M., Wu J., Chen S., Liu H., Zhukov A. // Opt. Lett. 2017. V. 42. N 17. P. 3319 3322.

[7] Wan Y., Inoue D., Jung D., Norman J.C., Shang C., Gossard A.C., Bowers J.E. // Photon. Res. 2018. V. 6. N 8. P. $776-781$.

[8] Liu A.Y., Herrick R.W., Ueda O., Petroff P.M., Gossard A.C., Bowers J.E. // IEEE J. Sel. Top. Quantum Electron. 2015. V. 21. N 6. P. 1900708.

[9] Tanabe K., Watanabe K., Arakawa Y. // Sci. Rep. 2012. V. 2. P. 349. 
[10] Zhang C., Liang D., Kurczveil G., Bowers J.E., Beausoleil R.G. // IEEE J. Sel. Top. Quantum Electron. 2015. V. 21. N 6. P. 1502607.

[11] Zou L.-X., Huang Y.-Z., Liu B.-W., Lv X.-M., Ma X.-W., Yang Y.-D., Xiao J.-L., Du Y. // Opt. Express. 2015. V. 23. N 3. P. 2879-2888.

[12] Надточий А.М., Крыжсановская Н.В., Максимов М.В., Жуков А.Е., Моисеев Э.И., Кулагина М.М., Вашанова К.А., Задиранов Ю.М., Мухин И.С., Аракчеева Е.М., Livshits D., Липовский A.A. // Письма в ЖТФ. 2013. Т. 23. B. 18. C. 70-77.

[13] Moiseev E.I., Kryzhanovskaya N.V., Nadtochiy A.M., Maximov M.V., Zhukov A.E., Shostak I.I., Kulagina M.M., Savel'ev A.V., Vashanova K.A., Lipovskii A.A. // J. Phys.: Conf. Ser. 2014. V. 541. P. 012049.

[14] Ouyang D., Ledentsov N.N., Bimberg D., Kovsh A.R., Zhukov A.E., Mikhrin S.S., Ustinov V.M. // Semicond. Sci. Technol. 2003. V. 18. N 12. P. L53-L54.

[15] Zhukov A.E., Kovsh A.R., Maleev N.A., Mikhrin S.S., Ustinov V.M., Tsatsul'nikov A.F., Maximov M.V., Volovik B.V., Bedarev D.A., Shernyakov Yu.M., Kop'ev P.S., Alferov Zh.I., Ledentsov N.N., Bimberg D. // Appl. Phys. Lett. 1999. V. 75. N 13. P. $1926-1928$. 